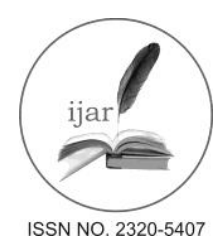

\section{Journal homepage:http://www.journalijar.com}

Journal DOI:10.21474/IJAR01

\section{RESEARCH ARTICLE}

INTERNATIONAL JOURNAL

OF ADVANCED RESEARCH

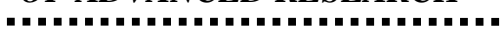

\title{
Knowledge and attitude of first aid skills among health science students at Taibah University, Al-Madinah ,
} Saudi Arabia.

Amal Salem Alhejaili and Shoroog Abdulrazzaq Alsubhi.

\section{Manuscript Info}

Manuscript History:

Received: 12 May 2016

Final Accepted: 19 June 2016

Published Online: July 2016

Key words:

First aid knowledge; awareness presentation; health science colleges.

*Corresponding Author

Amal Salem Alhejaili.

\begin{abstract}
Background: First aid is a simple steps that done outside the hospital setting to save someone's life or prevent condition from worsening until arrival of health care providers.

Objective: Assess awareness about first aid knowledge among the female students of health science colleges before and after awareness presentation.

Methodology: A cross-sectional study was done among the female students of health science colleges through pre- and post- awareness assessments. Thirteen selected multiple choice questions about various emergency accidents were included in the questionnaire. The awareness presentation contained how to deal with the various emergency accidents, was sent to the students via email and the comparison before and after the awareness presentation was analyzed.

Results: A total of 110 female students participated in this study. Only, 58 students completed the answers of the questionnaire to compare between pre- and post -awareness with the response rate of $52.7 \%$. There was a statistically significantly improvement in the best dealing with many situations such as checking for any hazards before doing first aid, loss of consciousness if victim can breathe or not, applying pressure in bleeding limb, supporting the fractured bone with a cushion, cooling the burn under cold water, putting the victim in safe place in convulsion and sit the patient and give him the medication in asthmatic attack.

Conclusion: This study showed inadequate knowledge about first aid among the female students. Health science students at Taibah University need first aid training program in their curriculum toimprove the basic skill about it.
\end{abstract}

Copy Right, IJAR, 2016,. All rights reserved.

\section{Introduction:-}

First aid is a quick, temporary and simple steps with minimal or no medical equipment that done outside the hospital setting to save someone's life or at least relive pain and prevent condition from worsening until arrival of health care providers that is the main aim of first aid $\{3\}$.

The future health care providers in the community are students of health science collages . First aid is not difficult, it is need a good attitude and simple steps with adequate knowledge and skills that make anyone deal with any accidents $\{1\}$.

Health science student generally and medical student especially even in their early years of studying are expected by general public to know how to do first aid to an injured patient and save live . 
In this study, the most common accidents that usually people face it in their life was specified .Basic first aid in emergency of bleeding, choking, seizure, hypoglycemic attack, burns, fractures, nasal bleeding, poisoning, asthmatic attack and fainting should be known by everyone. $\{3\}$

\section{Objective:-}

To evaluate the knowledge of first aid among female health science students at Taibah University before and after awareness presentation. $\{3\}$

\section{Methodology:-}

This study was to assess " awareness about first aid skills among the female students of health science collages at Taibah University in Al-Medina between November 2015- to February 2016. The selected health science colleges were collage of medicine, nursery and dentistry. This research was approved by the college of medicine research council ethical committee of Taiba University $\{3\}$.

The participants in this study were approximately 110 randomly chosen with ages ranging between 19 and 26 years $\{1\}$. A questionnaire was distributed to 110 female students through " collective data collection " and 110 female students were participated and the post-awareness which was "emailed " questionnaire distributed to 110 students and the participated were 58 students. The questionnaire include 19 questions were ranging between 5 open ended questions and 14 closed ended which is multiple choice questions selected about burn, bleeding, choking, fracture, nasal bleeding, seizure, poisoning, asthmatic attack, hypoglycemic attack and loss of consciousness. The awareness program was an educational material which was provided to students along with the questionnaire. This material was presentation included information regarding first aid and appropriate way to deal with it in each emergency case which is selected in the questionnaire. The data were coded, entered and processed on a computer using SPSS " version 19, IBM corp, united state ". Data was summarized using mean, standard deviation and range. A chi square test was used to analyze categorical data, and paired ' $t$ ' test was used for variable analysis. P value of $<.05$ was considered to indicate a statistical significance $\{3\}$.

\section{The result:-}

A total of 110 female students participated in this study. 43 (39.1\%) were medical , 37 (33.6\%) were dentist and $30(27.3 \%)$ were nurses. $\{1\}$ Only, 58 students completed the answers of the questionnaire to compare between pre- and post -awareness with the response rate of $52.7 \%$.

98.2\% of the student reported that they had information about first aid in the pre-awareness assessment .The source of information were differ, $53.6 \%$ had their information from internet website.

$79.1 \%$ thought their information is not sufficient .Sixty nine of the student agreed that first aid can save victim's live. $16.4 \%$ of the student answered that they had the ability to do first aid in case of emergency situation and $72.7 \%$ they were knew red crescent number .

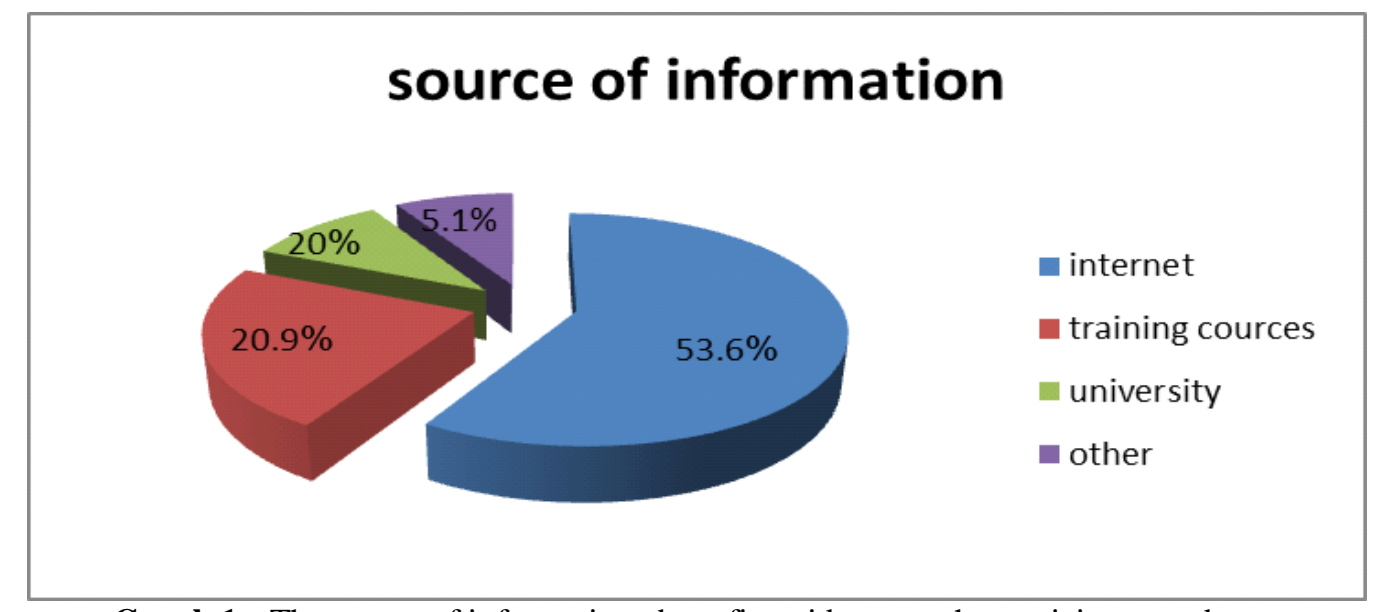

Graph 1:- The source of information about first aid among the participant students. 
Table 1:- Showing the 110 student's answer before awareness presentation .

\begin{tabular}{|c|c|c|}
\hline Question & $\begin{array}{l}\% \text { of } \\
\text { Right answer }\end{array}$ & $\begin{array}{l}\% \text { of } \\
\text { Wrong answer }\end{array}$ \\
\hline - Do you have any information about first aid skill? & $98.2 \%$ & $1.8 \%$ \\
\hline - Do you think the first aid has rule to save the victim's live ? & $69.1 \%$ & $30.9 \%$ \\
\hline - Do you think that your knowledge is sufficient ? & $20.9 \%$ & $79.1 \%$ \\
\hline - Do you know the Saudi emergency call number? & $72.7 \%$ & $27.3 \%$ \\
\hline - Do you think you have the ability to do first aid in emergency case? & $16.4 \%$ & $83.7 \%$ \\
\hline $\begin{array}{l}\text { - What is the first thing you should do before you consider administering } \\
\text { First Aid? }\end{array}$ & $37.3 \%$ & $62.7 \%$ \\
\hline $\begin{array}{l}\text { - What should you do if someone is unconscious and breathing to help him } \\
\text { keep the airway open?(2) }\end{array}$ & $68.2 \%$ & $31.8 \%$ \\
\hline - What should you do if someone is unconscious and not breathing?(2) & $68.2 \%$ & $31.8 \%$ \\
\hline $\begin{array}{l}\text { - The recovery position is often utilized for casualties but what is its main } \\
\text { advantage being? }\end{array}$ & $64.5 \%$ & $35.4 \%$ \\
\hline - How to help someone bleeding from a wound?(2) & $47.3 \%$ & $52.7 \%$ \\
\hline - What should you do if case of fracture ?(2) & $89.1 \%$ & $10.9 \%$ \\
\hline - What is the proper thing you have to do in case of burn?(2) & $73.6 \%$ & $26.4 \%$ \\
\hline - What should you do to help someone who is choking? & $75.5 \%$ & $24.5 \%$ \\
\hline - What should you do in case of epistaxis? & $55.5 \%$ & $44.5 \%$ \\
\hline $\begin{array}{l}\text { - What is the best course of action if we witness a casualty having a } \\
\text { seizure? }\end{array}$ & $70.9 \%$ & $29.1 \%$ \\
\hline - What should you do to help victim's with asthmatic attack?(2) & $68.2 \%$ & $31.9 \%$ \\
\hline - If someone is having a hypoglycemic attack, what should you do? & $95.5 \%$ & $4.5 \%$ \\
\hline $\begin{array}{l}\text { - What the important information you have to know in case of swallow } \\
\text { poison or harmful substance?(2) }\end{array}$ & $83.6 \%$ & $16,4 \%$ \\
\hline
\end{tabular}

In pre-awareness study which include 110 students the wrong reflects on skills and attitude of how to manage various emergency case were shown as in first thing providers should do before consider administering first aid $33.6 \%$ were answered to request for an ambulance to attend, $29.1 \%$ answered to check to ensure the casualty is stable.

In case of loss of consciousness and victim can breath $30 \%$ they tended to make sure nothing is obstructing the airway. In other side, if victim is loss of consciousness and cannot breath $19.1 \%$ answered to call ambulance and wait for the paramedics to arrive , $12.7 \%$ thought to call ambulance and put victim in recovery position .

Advantage of recovery position $30.9 \%$ thought it is a good stable position which can easily monitor a casualty . In case of bleeding due to injury $52.7 \%$ thought to remove any foreign body from site of bleeding . $6.4 \%$ tended to dress the bone fracture and $4.5 \%$ were tended to ask about pain .

In case of burn, $26.4 \%$ answered to wipe the burn with antiseptic wipes . In choking $20.9 \%$ were thought to inserting the finger to the back of the victim's throat trying to dislodge the foreign body .

In epistaxis $24.5 \%$ thought to make casualty lean backward and pinch the nose , $20 \%$ thought to put a cotton in nose and breath from the mouth. In epilepsy management, $23.6 \%$ answered that restrain the victim. In asthmatic attack $25.5 \%$ thought the victim have to sitting in a comfortable position and breathing into a paper bag

In hypoglycemic attack .9\% answered to give the victim a low-calorie drink. If victim ingest a toxic substance 9.1 $\%$ were thought to ask what that materials have taken, when and why .

Graph (2): The percentage of the wrong pre-awareness answers about first aid management.

Q1 red crescent number /

Q2 the first thing should do before consider administering First Aid /

Q3 is unconscious and breathing / 
Q4 is unconscious and they are not breathing /

Q5 The advantage of recovery position /

Q6 someone is bleeding from a wound /

Q7 broken a leg/ Q8 someone who has a burn /

Q9 someone who is choking /

Q10 bleeding from a nose /

Q11 action if a casualty having a seizure /

Q12 someone has an asthma attack /

Q13 someone has a hypoglycemic attack / Q14 a person has swallowed poison

The comparison between pre- and post-awareness presentation about first aid study which include 58 female students , $33(56.9 \%)$ were medical , $19(32.8 \%)$ were dentist and $6(10.3 \%)$ were nurses .

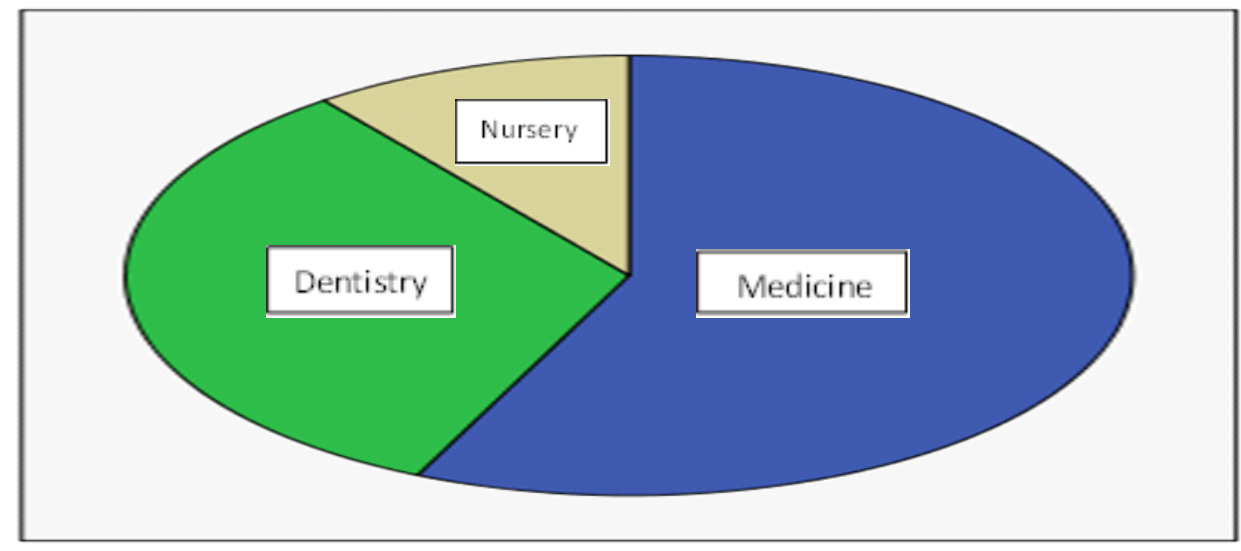

Graph 3:- The distribution of the participant students .

96.6\% of student answered they had information about first aid before awareness compared to one hundred percent after awareness $(\mathrm{p}=.15)$, in spite of this large percentage, their answers about dealing with emergency situations showed the deficient in their knowledge. $77.6 \%$ of the student still thought that first aid can save victim's live $(\mathrm{p}=.84)$, even in those who's management situation improved by $50 \%$ and became sufficient about First Aid ( $15.5 \%$ pre vs. $65.5 \%$ post , $\mathrm{P}=.00$ ) .

The improvement was fifty five percent of the student who became more familial to do first aid in emergency case after awareness about the technique (pre $20.7 \%$ vs. $75.9 \%$ post, $\mathrm{p}=.000$ ), and twenty percent of them became more alert about red crescent number, (pre $67.2 \%$ vs. Post $96.6 \% \mathrm{p}=.000$ ). Forty six percent of the student didn't know that they have to check for any hazards and dangers before going to do first aid , after awareness the observed improvement was twenty four percent (pre $46.6 \%$ vs. Post $70.7 \%, \mathrm{p}=.005$ ) . In case of loss of consciousness while the victim can breath the observed improvement was twenty-two percent became more alert to check first if the victim is breathing or not then call the ambulance for help , ( $62.1 \%$ pre vs. $84.5 \%$ post , $\mathrm{p}=.003$ ). In other hand ,if victim is loss of consciousness and cannot breath twentyfour percent became knew that they have to call ambulance first then push in the center of the chest 30 compressions as a regular rate,$(72.4 \%$ pre vs. $96.6 \%$ post, $\mathrm{p}=.002)$.

In advantage of recovery position which is to make sure that airway is patent the observed improvement was twenty-four percent became more alert than those before awareness, ( pre 63.8\% vs. 87.9\% post, p=.117). In case of bleeding due to injury $53.4 \%$ were aware that direct pressure is applied and the injured limb raised above the level of the heart ,post- awareness became $77.6 \%,(\mathrm{p}=.009)$. In case of bone fracture $98.3 \%$ knew to support the affected limb using a cushion or some clothing, compare to those before awareness $84.5 \%$ ( $\mathrm{p}=.009$ ). In case of burn $65.5 \%$ pre-awareness were knew to cool the burn under cold water for 10 minutes which act to stop the burning process , while $86.2 \%$ post-awareness chose the correct answer, $(\mathrm{p}=.004)$.

In choking $67.2 \%$ were knew to hit the victim firmly on their back between the shoulder to dislodge the foreign body, while in post-awareness answered $75.9 \%$ choose the correct option, $(\mathrm{p}=.517)$. In epistaxis fifty-seven 
percent became more oriented that the victim should pinch the nose and lean forward, ( $20.7 \%$ pre vs. 77.6 $\%$ post , $\mathrm{p}=00)$.

In epilepsy management $87.9 \%$ post- awareness answered that the victim be in safe place and not to restrict them ,while in pre-awareness $60.3 \%$ were knew the correct answer, $(\mathrm{p}=.001)$. In asthmatic attack the person should take his medication and sit in a comfortable position $63.8 \%$ pre-awareness choose the correct answer while in post-awareness they became $87.9 \% \quad(p=.002 .($

In hypoglycemic attack $93.1 \%$ knew to give the victim a sugary drink or food to raise the blood glucose level , in comparison between pre- and post-awareness showed a significant difference, post-awareness answered were $98.3 \%(\mathrm{p}=.024)$. In case of ingestion of toxic substance $84.5 \%$ knew that it should be important to ask about the cause that make the victim ingested these material, time of ingestion and amount of the substance, while in postawareness $93.1 \%$ became more alert $(\mathrm{p}=.18)$ but didn't show significant difference.

Table 2:-Comparison between the fifty eight student's answers to the questions before and after the awareness presentation.

\begin{tabular}{|c|c|c|c|c|}
\hline Question & $\begin{array}{r}\text { Pre answer } \\
\%\end{array}$ & $\begin{array}{r}\text { Post } \\
\% \text { answer }\end{array}$ & $\mathrm{P}$ value & $\begin{array}{r}95 \% \text { Confidence } \\
\text { Interval }\end{array}$ \\
\hline Do you have any information about first aid skill? & $96.6 \%$ & $100 \%$ & 527. & $083 \quad .-014 .-$ \\
\hline $\begin{array}{l}\text { Do you think the first aid has rule to save the victim's } \\
\text { live? }\end{array}$ & $77.6 \%$ & $77.6 \%$ & 84. & 157. -191.- \\
\hline Do you think that your knowledge is sufficient? & $15.5 \%$ & $65.5 \%$ & 157. & 665. -.335 \\
\hline $\begin{array}{l}\text { Do you know the Saudi emergency call number(red } \\
\text { crescent)? }\end{array}$ & $67.2 \%$ & $96.6 \%$ & 000. & 423. -.163 \\
\hline $\begin{array}{l}\text { Do you think you have the ability to do first aid in } \\
\text { emergency case? }\end{array}$ & $20.7 \%$ & $75.9 \%$ & 000. & 851. -.425 \\
\hline $\begin{array}{l}\text { What is the first thing you should do before you } \\
\text { consider administering First Aid? }\end{array}$ & $46.6 \%$ & $70.7 \%$ & 005. & $-127 .-\quad-666 .-$ \\
\hline $\begin{array}{l}\text { What should you do if someone is unconscious and } \\
\text { breathing to help him keep the airway open?(2) }\end{array}$ & $62.1 \%$ & $84.5 \%$ & 003. & 710. -.152 \\
\hline $\begin{array}{l}\text { What should you do if someone is unconscious and not } \\
\text { breathing?(2) }\end{array}$ & $72.4 \%$ & $96.6 \%$ & 002. & 527. -.128 \\
\hline $\begin{array}{l}\text { The recovery position is often utilized for casualties but } \\
\text { what is its main advantage being? }\end{array}$ & $63.8 \%$ & $87.9 \%$ & 117. & 312. $-036 .-$ \\
\hline How to help someone bleeding from a wound?(2) & $53.4 \%$ & $53.4 \%$ & 009. & $-062 .--421 .-$ \\
\hline What should you do if case of fracture ?(2) & $84.5 \%$ & $98.3 \%$ & 009. & $-053 .--361 .-$ \\
\hline $\begin{array}{l}\text { What is the proper thing you have to do in case of } \\
\text { burn?(2) }\end{array}$ & $65.5 \%$ & $86.2 \%$ & 004. & 714. -.148 \\
\hline What should you do to help someone who is choking? & $67.2 \%$ & $75.9 \%$ & 517. & 421. --.215 \\
\hline What should you do in case of epistaxis? & $20.7 \%$ & $77.6 \%$ & 000. & $-036 .--516 .-$ \\
\hline $\begin{array}{l}\text { What is the best course of action if we witness a } \\
\text { casualty having a seizure? }\end{array}$ & $60.3 \%$ & $87.9 \%$ & 001. & 847. -.222 \\
\hline $\begin{array}{l}\text { What should you do to help victim's with asthmatic } \\
\text { attack?(2) }\end{array}$ & $63.8 \%$ & $87.9 \%$ & 002. & 805. -.195 \\
\hline $\begin{array}{l}\text { If someone is having a hypoglycemic attack, what } \\
\text { should you do? }\end{array}$ & $93.1 \%$ & $98.3 \%$ & 024. & 161. -.012 \\
\hline $\begin{array}{l}\text { What the important information you have to know in } \\
\text { case of swallow poison or harmful substance?(2) }\end{array}$ & $84.5 \%$ & $93.1 \%$ & .18 & $-.057-.299$ \\
\hline
\end{tabular}

\section{Discussion:-}

As the best of our knowledge, no similar studies regarding awareness of first aid measures among medical students have been done in Saudi Arabia before .Other studies were conducted to estimate the knowledge and attitude of medical students about the basic life support (BLS) $\{3\}$, another study studied first aid measures among secondary school students of Saudi Arabia $\{7\}$.

The pre-awareness results of this study showed that the majority of the female students (98.2\%) thought that they had previous knowledge about first aid, only $16.4 \%$ reported to have the ability to do first aid in emergency case . A Peruvian study reported that $52.5 \%$ of medical students had prior training in management of medical emergencies, 
however, $60.4 \%$ of them had poor knowledge about first aid. Abd El-Hay determined that all students had poor mean score of knowledge and practice regarding first aid and basic life support $\{8\}$.

In this study, the knowledge of first aid management in suspected bone fractures was about $89.1 \%$ and in bleeding was $47.3 \%$ had good knowledge, similar studies in Mangalore in south India was 12.5\% for both management of fracture and bleeding $\{3\}$, study in Kuwait university for knowledge about wound bleeding was $42.3 \%$ and for bone fracture was $59.6 \%\{5\}$.The first aid management of burns was known correctly by $73.6 \%$ students in this study, as against $23.2 \%$ in an Irish study, $13.8 \%$ in south Indian study and $32.6 \%$ in Kuwait university. Analysis of knowledge about first aid management of epistaxis $55.5 \%$ had good knowledge, against $13.8 \%$ in Mangalore university study in south India $\{3\}$.

First aid following accidental choking by a foreign body was good in $75.5 \%$ in this study against $43.6 \%$ cases in the Karachi based study, $53.4 \%$ in the Peruvian study and $13.2 \%$ in south Indian study $\{3\}$.This study also reported that $83.6 \%$ of the students had good knowledge of first aid management in cases of accidental ingestion of poisons as against $15.8 \%$ in study of south India study.

With respect to correct management of convulsions, $70.9 \%$ was good in this study, as compared to $24.8 \%$ medical students in the Karachi and $13.8 \%$ students in south Indian study. In correct management of recovery position, $24.8 \%$ medical students in the Karachi study were knew of recovery position as against $64.5 \%$ students in this study. The majority of students in this study knew management of victims with hypoglycemic attack sufficiently with rate of $95.5 \%$ compared to $61 \%$ in Kuwait university study. Manage victim in case of unconsciousness and breath by $68.2 \%$ against $16.5 \%$ in Kuwait university study.

After the awareness program which was submitted to the students in this study, significant improvement were shown in the knowledge of the majority of the first aid questions. This is in agreement with Abd El-Hay et al. \{8\} and Bolling et al. $\{9\}$ who reported that first aid training resulted in improvement of the knowledge and attitude of the students. Some knowledge didn't show statistically improvement and this could be attributed that regular workshops were needed for the students and refresh their knowledge continuously.

\section{Limitation of the study:-}

The male student was not included in this study because they are in separate building. Regular workshops with the students were not possible due to the authors and the student's load of their academic courses.

\section{Conclusion:-}

This study showed the inadequate knowledge about first aid and the lack of the main concept and technique of first aid among the female medical students. The efficiency of the awareness education program was indicated by the improvement in dealing with various emergency situations in post-awareness assessment.

\section{Recommendation:-}

First aid training program should be add in the curriculum of the health science students at Taibah University to improve the knowledge and basic skill about first aid.

\section{Acknowledgment:-}

Acknowledge to Prof. Magda HassaneinMetwally Youssef for the support and help during this study. Also, the authors acknowledge the student from college of medicine, density and nursery for their participation .

\section{References:-}

1. Swetha C, Suchitra M N, Sahana, B N. (2015). A Study On Assessment Of Knowledge Attitude And Practices Regarding First Aid Among Nursing Students. International Journal of Current Research; 7(06): 16873-16875.

2. British Red Cross, Everyday-First-Aid , URL (http://www.redcross.org.uk/What-wedo/First-aid/Everyday-First-Aid/Test-your-first-aid-skills\#feedbackform ) Retrieved on 2016.

3. Joseph N, Kumar GS, Babu YPR, Nelliyanil M, Bhaskaran U (2014). Knowledge of First Aid Skills Among Students of a Medical College in Mangalore City of South India. Ann Med Health Science Research; 4(2): 162- 166. 
4. Abbas A, Bukhari SI, Ahmad F (2011). Knowledge of first aid and basic life support amongst medical students: a comparison between trained and un-trained students. J Pak Med Assoc; 61(6):613-6.

5. Al-Khamees N (2006). A field study of first aid knowledge and attitudes of college students in Kuwait University, Freepatentsonline. College Student Journal Publisher;40(4)

6. Alanazi A, Alsalmeh M, Alsomali O, Almurshdi AM, Alabdali A, Al-Sulami M, Al-Nemer A, Al-Qusairy A, Aloraibi S, Iqbal Z (2014). Poor Basic Life Support Awareness among Medical and College of Applied Medical Sciences Students Necessitates the Need for Improvement in Standards of BLS Training and Assessment for Future Health Care Providers. Middle-East Journal of Scientific Research 21 (5): 848-854.

7. Mobarak A S, Afifi R M, Qulali A (2015). First Aid Knowledge and Attitude of Secondary School Students in Saudi Arabia Health; 7: 1366-1378.

8. Abd El-Hay S A, Ibrahim N A, Hassan L A (2015). Effect of Training Program Regarding First Aid and Basic Life Support on the Management of Educational Risk injuries among Students in Industrial Secondary Schools. IOSR Journal of Nursing and Health Science (IOSR-JNHS); 4(6); 32-43.

9. Bollig G, Wahl H A, Svendsen M V (2009). Primary School Children are Able to Perform Basic Life-Saving First Aid Measures, Resuscitation M J; 80: 689-92.

\section{Appendix}

"Knowledge of first aid skills among health science students at Taibah University"

This questionnaire will be used for research and publication .

Age

collage

Sex............

Department ............

10. Do you have any information about first aid skill ?

- Yes

No

11. If (yes) select the source of your information about first aid :

- Training course

- Internet

- Reading book

- Television

- University

Other

12. Do you think the first aid has rule to save the victim's live ?

- Yes

- Sometimes

- $\mathrm{No}$

13. Do you think you have the ability to do first aid in emergency case ?

- Yes

- No

14. Do you think that your knowledge is sufficient?

- Yes

- No

15. Do you know the Saudi emergency call number(red crescent) ?

- Yes

- No

16. What is the first thing you should do before you going to do First Aid?

- Check if the casualty is stable.

- Request for an Ambulance to attend.

- Check for any hazards and dangers ( put on gloves).

17. What should you do if someone is unconscious and breathing to help him keep the airway open?

- Tilt his head back after rolling on his side .

- Tilt his head back after lying him on front .

- Be sure there is nothing obstruct the nose.

18. What should you do if someone is unconscious and not breathing?

- Call 997 then push in the center of the chest 30 compressions as a regular rate .

- Call 997 then wait for help to arrive.

- Call 997 then tilt his head back after rolling him on side. 
19. The recovery position is often utilized for casualties but what is its main advantage being?

- It ensures the casualty is comfortable.

- It's a good stable position from which we can easily monitor a casualty.

- It maintains an open airway.

20. How to help someone bleeding from a wound?

- Let him bleeding.

- Apply direct pressure, bandage wound keep limb raised higher than heart level if possible.

- Apply direct pressure after removal of any embedded object from wound .

21. What should you do if case of fracture ?

- Check for pain by asking him to lean on their leg .

- Support the affected part by using a cushion or some clothing.

- Apply dressing to fracture and move causality to safe location

22. What is the proper thing you have to do in case of burn ?

- Bursting the blisters then wrap with clean plastic bag .

- Clean the burn with antiseptic solution .

- Cooling under running water for 10 minutes .

23. What should you do to help victim with choking?

- Try to dislodge the foreign body by inserting your finger to the back of the victim's throat .

- Help him drink some water to dislodge the object.

- Hitting his back firmly between the shoulder blades.

24. When you have someone is bleeding from a nose, what should you do ?

- Should lean backward and pinch the nose.

- Should lean forward and pinch the nose.

- Should put a cotton in nose and breath from his mouth .

25. What is the best course of action if we witness a casualty having a seizure?

- Restrain them.

- Let them have their seizure and ensure safe place .

- Try and give them their medication .

26. What should you do to help victim's with asthmatic attack?

- Ask the person to take his medication and sit in a comfortable position .

- Help the person breathe into a paper bag and sit in a comfortable position .

- Ask him to run around the block.

27. What should you do in case of hypoglycemic attack ?

- Let him drink a sugary or sweet food.

- Let him take a low-calorie drink .

- Let him eat carbohydrate like bread or pasta .

28. What the important information you have to know in case of swallowing poison or harmful substance?

- What he take, amount and time .

- What he taken, time and place .

- What he take, time and reason . 